\title{
ANALISIS PERSEDIAAN BAHAN BAKU PVC COMPOUND DENGAN METODE ECONOMIC ORDER QUANTITY (EOQ) UNTUK MENGETAHUI NILAI FREKWENSI NILAI PEMESANAN PADA PT XYZ
}

\author{
Taufik \\ Dosen Fakultas Teknik Program Studi Teknik Industri Universitas Pamulang \\ dosen01332@unpam.ac.id
}

\begin{abstract}
ABSTRAK
Persediaan bahan baku merupakan bagian dari industri yang bergerak dalam bidang manufaktur. PT. $\mathrm{XYZ}$ salah satunya perusahaan manufaktur yang memproduksi kabel dan PVC. Permasalahan yang ada masih kurangnya penyedia bahan baku yang senyawa dengan PVC. Untuk itu dalam penelitian ini menggunakan data kualitatif dan kuantitatif dalam pengumpulan data maupun dalam pengolahan data untuk mengetahui bahan baku yang ada diperusahaan. Penelitian ini bertujuan untuk mengetahui keamanan stok bahan baku pada saat frekuensi respon pembelian bahan baku saat ini dan jumlah kebutuhan bahan baku yang optimal, informasi biaya lengkap yang dikeluarkan dalam persediaan bahan baku perusahaan dan informasi pemesanan pada titik penataan ulang. Metode yang digunakan dalam penelitian ini yang tepat adalah menggunakan Economic Order Quantity (EOQ), pemilihan metode ini dianggap mampu menyelesaikan masalah yang ada. Selanjutnya dengan menghitung Period Order Quantity (POQ) maka didapat solusi dalammengelola persediaan bahan baku dengan efisiensi biaya Total Cost Inventory (TCI) yang akan didapat dengan pengematan keefektifitasan frekuensi supaya lebih terjadwal. Hasil dalam penelitian ini adalah dengan pengumpulan data selama satu tahun didapat hasil biaya persediaan dengan perhitungan POQ optimal dimana EOQ bahan baku polyvinyl Chloride sebesar Rp 29.100.293,99 dalam satu tahun. Untuk bahan baku plasticizer didapatkan sebesar Rp 27.594.547,87 per tahun. Sedangkan untuk polyvinyl Cloride nilai POQ sebesar Rp 24.897.22 per tahun dan plasticiezer sebesar Rp 17.223.066,03 per tahun.
\end{abstract}

Kata Kunci: Pengendalian Persediaan, Cost of Activity (ABC), (EOQ).

\section{PENDAHULUAN}

PT. XYZ merupakan perusahaan yang bergerak dibidang industri Manufacture, dengan memproduksi kabel dan PVC Compound. Bahan baku yang digunakan dalam proses produksi Manufacture perusahaan bermacam macam jenis dan dalam pelaksanaan produksi bahan baku dalam keadaan tersedia untuk memenuhi kebutuhan diproses produksi. Perusahaan harus bisa mengelola persediaan dengan baik agar dapat memiliki persediaan yang seoptimal mungkin demi kelancaran operasi perusahaan dalam jumlah, waktu, mutu yang tepat serta dengan biaya yang serendah rendahnya.

Persediaan bahan baku pada PT. XYZ belum direncanakan dengan baik sehingga persediaan bahan baku kurang optimal belum sesuai standard yang diharapkan yaitu selisih yang digunakan sebagai stock material maksimal hanya $15 \%$ dari kebutuhan proses produksi. Kebutuhan bahan baku proses produksi PVC Compound dilihat dalam periode Januari-Desember 2018 dapat dilihat pada Tabel 1.1 berikut ini:

Tabel 1.1 Kebutuhan Bahan Baku Tahun 2018

\begin{tabular}{|c|l|c|c|c|c|}
\hline No & Material & $\begin{array}{c}\text { Pemesanan 1 } \\
\text { tahun (Kg) }\end{array}$ & $\begin{array}{c}\text { Kebutuhan 1 } \\
\text { tahun (Kg) }\end{array}$ & Selisih (Kg) & $\begin{array}{c}\text { Persentase } \\
\text { Selisih(\%) }\end{array}$ \\
\hline 1 & Polyvinyl chloride & $3.750 .000,00$ & $3.064 .025,40$ & $685.974,60$ & $22,39 \%$ \\
\hline 2 & Plasticizer 1 & $1.966 .860,00$ & $1.637 .219,00$ & $329.641,00$ & $20,13 \%$ \\
\hline 3 & Plasticizer PC & $270.000,00$ & $269.545,24$ & 454,76 & $0,17 \%$ \\
\hline 4 & Plasticizer NP & $268.850,00$ & $268.666,83$ & 183,17 & $0,07 \%$ \\
\hline 5 & Plasticizer CP & $323.054,50$ & $318.920,00$ & $4.134,50$ & $1,30 \%$ \\
\hline 6 & Filler & $2.122 .400,00$ & $2.106 .818,20$ & $15.581,80$ & $0,74 \%$ \\
\hline 7 & Stabilizer & $250.240,00$ & $250.140,32$ & 99,68 & $0,04 \%$ \\
\hline 8 & Lubricant & $18.150,00$ & $7.588,80$ & $10.561,20$ & $139,17 \%$ \\
\hline 9 & Ultra Violet 1 & $5.980,00$ & $5.475,69$ & 504,31 & $9,21 \%$ \\
\hline 10 & Pigment BK & $21.600,00$ & $19.784,95$ & $1.815,05$ & $9,17 \%$ \\
\hline \multicolumn{7}{|c|}{ Total } & $\mathbf{8 . 9 9 7 . 1 3 4 , 5 0}$ & $\mathbf{7 . 9 4 8 . 1 8 4 , 4 3}$ & $\mathbf{1 . 0 4 8 . 9 5 0 , 0 7}$ & \\
\hline
\end{tabular}

Sumber: PT. XYZ 
Berdasarkan Tabel 1.1 terdapat tiga bahan baku yang melewati ketentuan perusahaan yaitu Polyvinyl chloride selisih 22,39\%, Plasticizer 1 selisih 20,13\%, Lubricant selisih $139,17 \%$, safety stock kurang diperhitungkan dari total kebutuhan sehingga berpotensi besar mengalalami shortage yang berakibat keterlambatan target pengiriman kepada Customer dan Stock-out akan berdampak kegagalan produk berupa hasil produk Vorius atau hasil kasar dikarenakan terlalu lama tersimpan di gudang, bahan baku dari PVC Compound adalah bahan kimia yang sangat mudah bereaksi sehingga akan membutuhkan biaya-biaya yang harus dikeluarkan untuk menjaga kualitas bahan baku selama penyimpanan bahan baku.

Persediaan optimal mampu mengefisiensikan biaya pengeluaran perusahaan seperti pemesanan dan biaya penyimpanan bahan baku. Dalam proses memperoleh laba yang optimal perusahaan mengalami kendala mengenai persediaan karena kebijakan sistem pengendalian persediaan masih belum dihitung secara baik sedangkan bahan baku yang memiliki nilai persediaan yang tinggi perusahaan harus dapat mengendalikan. Berdasarkan uraian latar belakang di atas, maka dalam penulisan penelitian ini penulis mengambil judul:

" Analisis Persediaan Bahan Baku Pvc Compound Dengan Metode Economic Order Quantity (EOQ) Untuk Mengetahui Nilai Frekwensi Nilai Pemesanan Pada PT XYZ”.

\section{DASAR TEORI}

\section{A. Pengertian Persediaan}

Menurut Pardede (2005), persediaan (inventory) adalah sejumlah barang atau bahan yang tersedia untuk digunakan sewaktu-waktu di masa yang akan datang. Sediaan terjadi apabila jumlah bahan atau barang yang diadakan (dibeli atau dibuat sendiri) lebih besar daripada jumlah yang digunakan (dijual atau diolah sendiri).

\section{B. Metode Economic Order Quantity (EOQ)}

Menurut Gitosudarmo (2012 : 101) EOQ sebenarnya adalah merupakan volume atau jumlah pembelian yang paling ekonomis untuk dilaksanakan pada setiap kali pembelian. Biaya-biaya untuk menyelenggarakan persediaan bahan baku ini sudah selayaknya diperhitungkan pula didalam penentuan besarnya persediaan bahan baku.
Dalam hubungannya dengan biaya-biaya persediaan ini, maka digunakan data biaya persediaan yaitu:

a. Biaya Penyimpanan (Holding Cost atau Carrying Cost)

Biaya penyimpanan per periode akan semakin besar bila jumlah atau kuantitas bahan yang disimpan semakin tinggi Misal: Biaya pemeliharaan bahan, biaya asuransi.

Biaya Penyimpanan $=\frac{\mathrm{Q}(\mathrm{K} \cdot \mathrm{U})}{2}$

Dimana:

Q: kuantitas bahan baku dalam setiap kali pembelian

$\mathrm{K}$ : Persentase biaya penyimpanan terhadap harga per unit Bahan

$\mathrm{U}$ : harga per unit bahan

b. Biaya Pemesanan (Ordering Cost) biaya persediaan akan semakin besar bila ferkuensi pemesanan bahan baku semakin besar. Misal: biaya bongkar bahan, biaya administrasi.

\section{Kerangka Fikir}

Kerangka berfikir pada penelitian ini sebagai berikut:

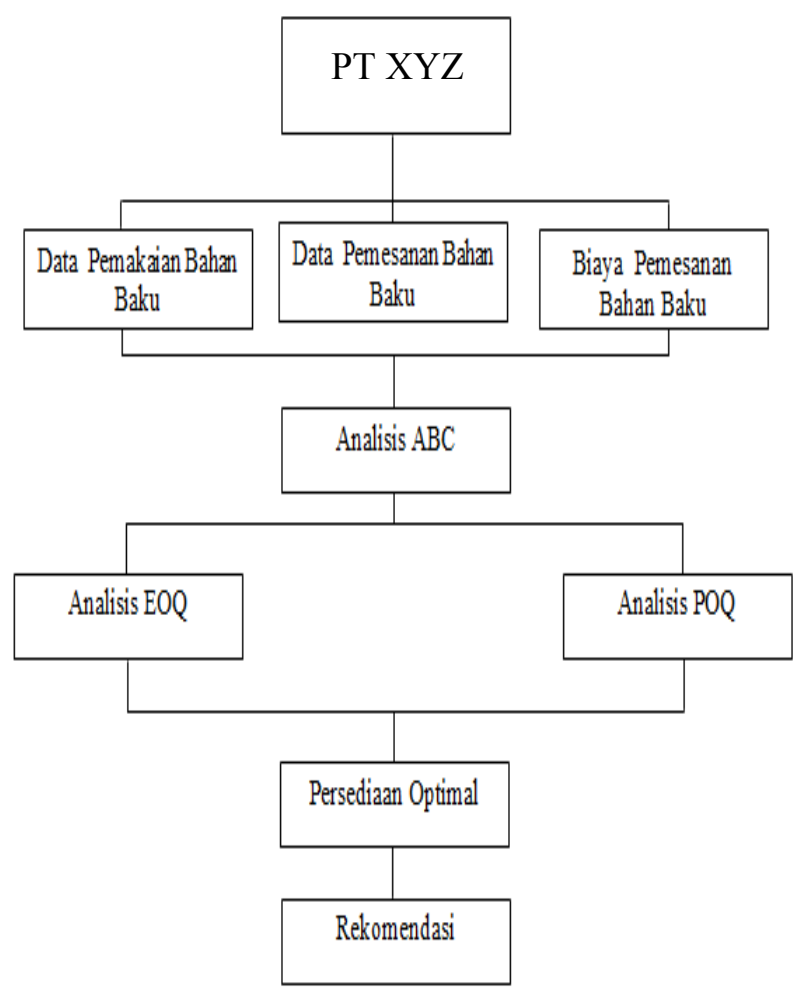

Sumber: Pengolahan Data Sendiri, 2018 Gambar 2.1. Kerangka Fikir 


\section{METODOLOGI PENELITIAN}

\section{A. Jenis Penelitian}

Jenis penelitian yang dilakukan penulis yaitu penelitian diskriptif, Peneliti hanya memusatkan perhatian kepada masalahmasalah actual sebagaimana adanya pada saat penelitian berlangsung dalam penelitian datadata yang diperlukan untuk membahas suatu masalah penelitian, data primer yang diperoleh secara langsung didapatkan dengan meminta keterangan serta mewawancarai karyawan yang terlibat langsung dengan manajemen logistik sehingga informasi yang didapat akan menambah kekayaan data, selain itu ada pula data sekunder yang tidak langsung diamati oleh peneliti yaitu data dokumentasi perusahaan yang data penelitian yang sudah lalu dan data lainnya.

Ketepatan memilih dan menentukan jenis sumber data akan menentukan kekayaan data yang diperoleh maka sebelum memulai penelitian ini peneliti melakukan beberapa langkah antara lain studi pendahuluan, studi lapangan , perumusan masalah, dan penetapan tujuan dan manfaat penelitian. Pengetahuan tentang sumber data merupakan hal yang sangat penting untuk diketahui agar tidak terjadi kesalahan dalam memilih sumber data yang sesuai dengan tujuan penelitian.

\section{B. Data dan Sumber Data}

Jenis data yang dibutuhkan dalam penelitian yaitu;

1. Data Kuantitatif

Data kuantitatif adalah jenis data yang dapat diukur atau dihitung secara langsung, yang berupa informasi atau penjelasan yang dinyatakan dengan bilangan atau berbentuk angka.

a. Data jumlah kebutuhan bahan baku pada Januari -Desember 2018;

b. Data harga bahan baku pada JanuariDesember 2018;

c. Data biaya pemesanan bahan baku pada Januari-Desember 2018;

d. Data biaya penyimpanan bahan baku pada Januari -Desember 2018.

2. Data Kualitatif

Data kualitatif adalah data yang berbentuk kata-kata atau yang berwujud pernyataanpernyataan verbal, bukan dalam bentuk angka.

a. Sejarah Perusahaan
PT. XYZ didirikan pada tahun 1993 sebagai perusahaan kabel presisi pertama dan satu-satunya di Indonesia yang memproduksi PVC Compound sendiri. Perusahaan memiliki visi mendukung negara dalam mengembangkan infrastruktur menjadikan seluruh mitra usaha kita sebagai pemenang untuk mencapainya tujuan tersebut salah satunya yaitu harus mengendalikan persediaan Economic Order Quantity (EOQ).

b. Struktur Organisasi, Tugas dan Tangung Jawabnya Struktur organisasi yang sistematis akan ikut andil dalam pengendalian persediaan dan dapat melakukan evaluasi. Struktur organisasi PT. XYZ menggunakan organisasi lini atau garis, artinya otorisasi atau kekuasaan mengalir dari pihak pimpinan organisasi sampai kepada unit organisasi yang ada dibawahnya. Begitu pula dengan pertanggungjawaban pekerjaan yang menjadi kewajibannya sebagai karyawan harus dilaporkan secara mengalir dari unit yang berada dibawahnya sampai pada tingkat yang paling atas berdasarkan tingkat jabatan yang dipegangnya agar tercapainya misi, tujuan, sasaran dan strategi perusahaan.

c. Prosedur Kerja

Tujuan prosedur kerja adalah menciptakan komitment mengenai apa yang dikerjakan oleh satuan unit kerja. Dengan adanya prosedur kerja di suatu organisasi atau perusahaan maka dapat dilakukan evaluasi dan peningkatan kualitas kerja yang lebih baik seiring dengan berjalannya waktu acuan untuk melaksanakan tugas pekerjaan sesuai dengan fungsi dan alat penilaian kinerja berdasarkan indikator indikator teknis, administrasif dan prosedural sesuai dengan tata kerja, prosedur kerja dan sistem kerja pada unit kerja yang bersangkutan. Prosedur kerja akan ikut mengatur pengendalian persediaan Economic Order Quantity (EOQ) .

Sumber data untuk kegiatan penelitian diperoleh dari data yang diperoleh atau dikumpulkan peneliti dari sumber-sumber yang telah ada yang digunakan untuk mendukung informasi. Data sekunder ini meliputi:

1. Sejarah perusahaan;

2. Struktur organisasi; 
3. Sirkulasi pemakaian bahan baku.

\section{Teknik Pengumpulan Data}

Metode pengumpulan data yang digunakan untuk memperoleh hasil penelitian yang baik, sehingga analisis tidak menyimpang dari tujuan yang telah ditentukan, adalah sebagai berikut:

1. Wawancara

Wawancara merupakan suatu cara untuk mengumpulkan data penelitian secara langsung dan mendalam dengan cara berkomunikasi (berbicara dan tatap muka) dengan pihak yang dianggap kompeten dan mengetahui permasalahan penelitian yang terjadi pada objek penelitian.

2. Dokumentasi

Cara memperoleh data dengan mencari dan mempelajari data yang berasal dari catatan dan dokumen yang dimiliki perusahaan yang dianggap penting dan menunjang penelitian. Dokumen tersebut berupa data sirkulasi pemakaian bahan baku pembuatan peroduk.

3. Studi Pustaka

Metode Studi Pustaka merupakan suatu teknik didalam pengumpulan data dengan kunjungan perpustakaan untuk membaca buku sebagai refrensi yang kemudian secara sistematis mencatat hal-hal yang menyangkut akan masalh atau pembahasan yang sesuai daengan hal yang sedang di analisis.

\section{Metode Analisis Data}

Analisis data yang digunakan dalam penelitian ini adalah analisis data kualitatif dan analisis kuantitatif. Pengolahan data menggunakan Microsoft Excel 2010.

1. Perhitungna Pemakain Bahan;

2. Perhitungan Bahan Tak bergerak;

3. Perhitungan Safety Stok;

4. Perhitungan Sirkulasi pemakaian bahan baku.

\section{E. Flow Chat Penelitian}

Untuk mempermudah alur dalam penelitian maka dapat dilihat flow chart penelitian berikut:

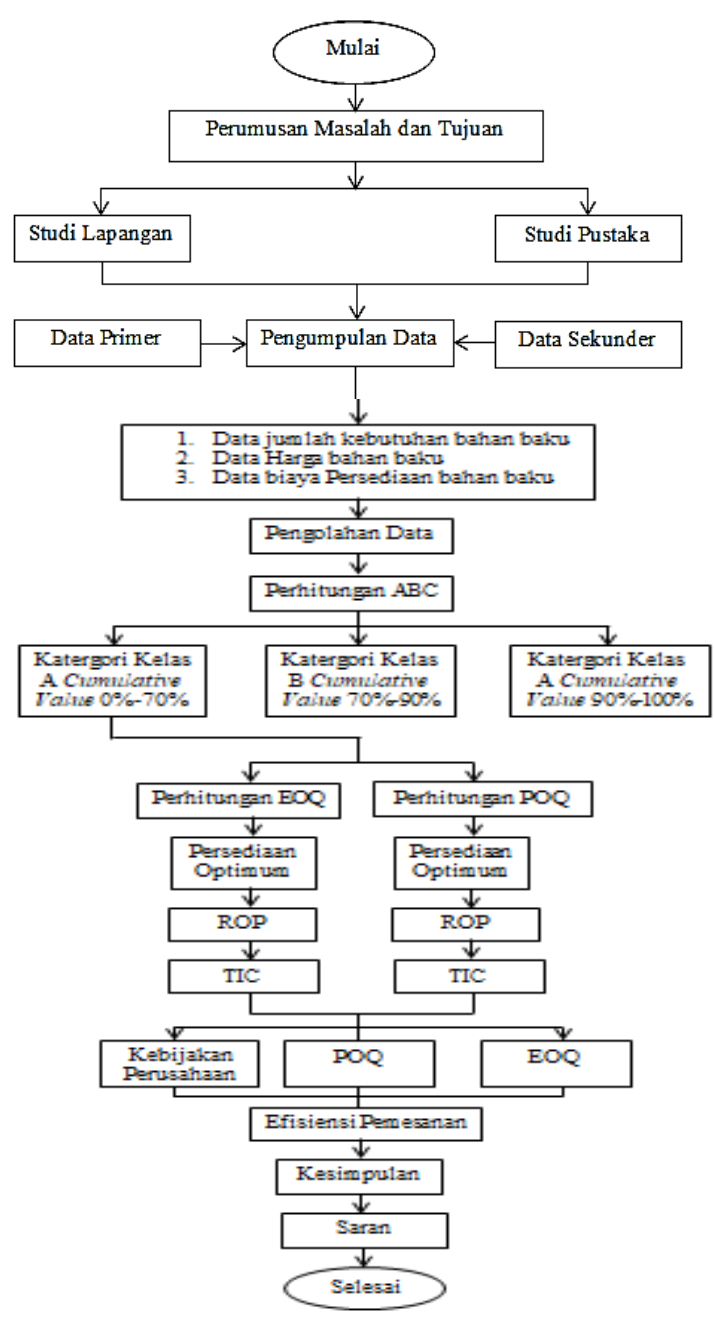

(Sumber: Pengolahan Data Sendiri, 2018)

Gambar 3.1. Bagan Alir Penelitian

\section{HASIL DAN PEMBAHASAN}

\section{A. Perhitungan Metode Activity Base Costing (ABC)}

Tabel 4.1 Pengelompokan Perhitungan Bahan Baku PVC Compound berdasarkan Metode Activity Base Costing (ABC) Bulan Jauari-

Desember 2018.

\begin{tabular}{|l|l|c|c|c|c|c|c|}
\hline No & Bahan Baku & $\begin{array}{c}\text { Pemakaian } \\
(\mathrm{Kg})\end{array}$ & $\begin{array}{c}\text { Harga } \\
\text { Per kg } \\
(\mathrm{Rp})\end{array}$ & $\begin{array}{c}\text { Nilai Pembelian } \\
(\mathrm{Rp})\end{array}$ & $\begin{array}{c}\text { Nilai } \\
\text { Persentase } \\
(\%)\end{array}$ & $\begin{array}{c}\text { Nilai } \\
\text { Kumulatif } \\
(\%)\end{array}$ & Kelompok \\
\hline 1 & Polyvinyl chloride & $3.064 .025,40$ & $15.000,00$ & $45.960 .381 .000,00$ & $39,70 \%$ & $39,70 \%$ & A \\
\hline 2 & Plasticizer 1 & $1.637 .219,00$ & $19.300,00$ & $31.598 .326 .700,00$ & $27,30 \%$ & $67,00 \%$ & A \\
\hline 3 & Stabilizer & $250.140,32$ & $39.800,00$ & $9.955 .584 .736,00$ & $8,60 \%$ & $75,60 \%$ & B \\
\hline 4 & Plasticizer NP & $268.666,83$ & $29.200,00$ & $7.845 .071 .436,00$ & $6,80 \%$ & $82,40 \%$ & B \\
\hline 5 & Plasticizer PC & $269.545,24$ & $27.800,00$ & $7.493 .357 .672,00$ & $6,50 \%$ & $88,90 \%$ & B \\
\hline 6 & Filler & $2.106 .818,20$ & $2.700,00$ & $5.688 .409 .140,00$ & $4,90 \%$ & $93,80 \%$ & C \\
\hline 7 & Plasticizer CP & $318.920,00$ & $11.800,00$ & $3.763 .256 .000,00$ & $3,30 \%$ & $97,10 \%$ & C \\
\hline 8 & Ultra Violet 1 & $5.475,69$ & $335.200,00$ & $1.835 .451 .288,00$ & $1,60 \%$ & $98,70 \%$ & C \\
\hline 9 & Lubricant & $7.588,80$ & $98.400,00$ & $746.737 .920,00$ & $0,60 \%$ & $99,30 \%$ & C \\
\hline 10 & Pigment BK & $19.784,95$ & $40.700,00$ & $805.247 .386,04$ & $0,70 \%$ & $100,00 \%$ & C \\
\hline \multicolumn{1}{|c|}{ Total } & $7.948 .184,43$ & - & $115.691 .823 .278,04$ & $100 \%$ & - & - \\
\hline
\end{tabular}


Dari hasil analisis data Bulan JanuariDesember 2018 mendapat kesimpulan dari klasifikasi kategori paling banyak pemakaiannya yang harus dikelola dengan ketat, hasil perhitungan Tabel 4.1

1. Pada klasifikasi A

Bahan baku PVC Compound dari bahan baku urutan ke 1-2 merupakan bahan baku kategori A adalah yang berada pada \% Cumulative Value 0\%-70\%, yang masuk kategori ini harus diprioritaskan selama pemesanan dibandingkan bahan baku yang lain yaitu Polyvinyl chloride $39,7 \%$ dan Plasticizer 1 67,0\%.

2. Pada klasifikasi B

Bahan baku PVC Compound dari bahan baku urutan ke 3-5 yang bahan baku masuk kategori B adalah yang berada pada \% Cumulative Value 70\%-90\% dapat dipesan sesuai standard untuk proses produksinya. Produk yang dari kelompok B yaitu Stabilizer 75,6\%, Plasticizer NP 82,4\%, Plasticizer PC 88,9\%.

3. Pada klasifikasi $\mathrm{C}$

Bahan baku PVC Compound dari bahan baku urutan ke 6-10 masuk klasifikasi C adalah yang berada pada \% Cumulative Value $90 \%-100 \%$ pemakaian bahan baku tetap diprioritaskan namun hanya bahan baku tersebut yang nilai perhitunganya paling kecil yaitu Filler 93,8\%, Plasticizer CP 97,1\%, Ultra Violet $198,7 \%$, Lubricant 99,3\%, Pigment BK 100,0\%.

Hasil dari klasifikasi Activity Based Costing (ABC) Polyvinyl chloride 39,7\% dan Plasticizer 1 67,0\%. Rincian dari hasil klasifikasi kelompok A yaitu sebagai berikut:

1. Kebutuhan Bahan Baku

Tabel 4.3 Pemakaian Polyvinyl Chloride

Periode Januari-Desember 2018

\begin{tabular}{|c|l|c|}
\hline No & \multicolumn{1}{|c|}{ Bulan } & Pemakaian (Kg) \\
\hline 1 & Januari & $185.500,10$ \\
\hline 2 & Februari & $334.185,60$ \\
\hline 3 & Maret & $248.152,20$ \\
\hline 4 & April & $237.600,00$ \\
\hline 5 & Mei & $244.875,00$ \\
\hline 6 & Juni & $353.625,00$ \\
\hline 7 & Juli & $296.625,00$ \\
\hline 8 & Agustus & $163.350,00$ \\
\hline 9 & September & $147.462,50$ \\
\hline 10 & Oktober & $368.250,00$ \\
\hline 11 & November & $235.100,00$ \\
\hline 12 & Desember & $249.300,00$ \\
\hline \multicolumn{2}{|c|}{ Total } & $\mathbf{3 . 0 6 4 . 0 2 5 , 4 0}$ \\
\hline
\end{tabular}

Sumber: Pengolahan Data Sendiri
Tabel 4.4 Pemakaian Plasticizer 1 Periode Januari-Desember 2018

\begin{tabular}{|c|c|c|}
\hline No & Bulan & Pemakaian (Kg) \\
\hline 1 & Januari & $110.018,00$ \\
\hline 2 & Februari & $134.396,00$ \\
\hline 3 & Maret & $118.074,50$ \\
\hline 4 & April & $139.980,50$ \\
\hline 5 & Mei & $107.425,50$ \\
\hline 6 & Juni & $184.346,00$ \\
\hline 7 & Juli & $188.904,00$ \\
\hline 8 & Agustus & $112.908,00$ \\
\hline 9 & September & $108.447,00$ \\
\hline 10 & Oktober & $197.081,00$ \\
\hline 11 & November & $95.950,00$ \\
\hline 12 & Desember & $139.688,50$ \\
\hline \multicolumn{2}{|c|}{ Total } & $\mathbf{1 . 6 3 7 . 2 1 9 , 0 0}$ \\
\hline
\end{tabular}

(Sumber: Pengolahan Data Sendiri Biaya Pemesanan

Tabel 4.5 Rincian Biaya Pemesanan Polyviny Chloride Tahun 2018

\begin{tabular}{|c|c|c|c|c|c|c|}
\hline \multirow[b]{2}{*}{ No } & \multirow[b]{2}{*}{ Biaya } & \multirow[b]{2}{*}{ Jumlah } & \multirow[b]{2}{*}{ Satuan } & \multicolumn{3}{|c|}{ Polyviny Chloride } \\
\hline & & & & $\begin{array}{c}\text { Biaya } \\
\text { Kes eluruhan } \\
\text { (Rp) }\end{array}$ & $\begin{array}{c}\text { Biaya Per } \\
\text { Pesan (Rp) }\end{array}$ & $\begin{array}{c}\text { Biaya } 1 \\
\text { Tahun (Rp) }\end{array}$ \\
\hline 1 & Internet & 375 & Mbps & 6.500 .000 & 216.666 & 2.599 .992 \\
\hline 2 & Telepon & Prabayar & Menit & 15.750 .000 & 525.000 & 6.300 .000 \\
\hline 3 & Administrasi & 1 & $\begin{array}{c}\text { Per } \\
\text { Bulan }\end{array}$ & - & 250.000 & 3.000 .000 \\
\hline \multicolumn{5}{|c|}{ Total } & 991.666 & 11.899 .992 \\
\hline
\end{tabular}

(Sumber: Pengolahan Data Sendiri

Tabel 4.6 Rincian Biaya Pemesanan Plasticizer 1 Tahun 2018

\begin{tabular}{|c|c|c|c|c|c|c|}
\hline \multirow{2}{*}{ No } & \multirow{2}{*}{ Biaya } & \multirow{2}{*}{ Jumlah } & Satuan & \multicolumn{3}{|c|}{ Plasticizer 1 } \\
\cline { 5 - 7 } & & & $\begin{array}{c}\text { Biaya } \\
\text { Keseluruhan } \\
\text { (Rp) }\end{array}$ & $\begin{array}{c}\text { Biaya Per } \\
\text { Pesan }\end{array}$ & $\begin{array}{c}\text { Biaya 1 } \\
\text { Tahun (Rp) }\end{array}$ \\
\hline 1 & Internet & 375 & Mbps & 6.500 .000 & 216.666 & 2.599 .992 \\
\hline 2 & Telepon & Prabayar & Menit & 15.750 .000 & 525.000 & 6.300 .000 \\
\hline 3 & Administrasi & 1 & $\begin{array}{c}\text { Per } \\
\text { Bulan }\end{array}$ & - & 150.000 & 1.800 .000 \\
\hline \multicolumn{3}{|c|}{ Total } \\
\hline
\end{tabular}

(Sumber: Pengolahan Data Sendiri di PT. Sinarmonas Industries)

\section{Biaya Penyimpanan}

Tabel 4.7 Rincian Biaya Penyimpanan Tahun 2018

\begin{tabular}{|c|c|r|r|}
\hline \multirow{2}{*}{ No } & \multirow{2}{*}{$\begin{array}{l}\text { Jenis Biaya } \\
\text { Dalam Satu } \\
\text { Gedung }\end{array}$} & Polyviny Chloride & Plas ticize r 1 \\
\cline { 3 - 4 } & & 241.560 .000 & 241.560 .000 \\
\hline 1 & Biaya Listrik & 2.700 .000 & 2.700 .000 \\
\hline 3 & $\begin{array}{l}\text { Biaya } \\
\text { Pemeliharaan }\end{array}$ & 840.000 & 840.000 \\
\hline 4 & Kartu Stock & 181.888 .176 & 181.888 .176 \\
\hline Tiaya & $\mathbf{4 2 6 . 9 8 8 . 1 7 6}$ & $\mathbf{4 2 6 . 9 8 8 . 1 7 6}$ \\
\hline
\end{tabular}

Sumber: Pengolahan Data Sendiri 
Total Biaya Persediaan Total Inventory Cost (TIC)

$$
\begin{aligned}
& \text { TIC Polyvinyl Chloride }=\left(\frac{D}{Q} S\right)+\left(\frac{Q}{2} H\right) \\
& T I C=\left(\frac{3.064 .025,40}{255.335,45} \times 991.666\right)+\left(\frac{255.335,45}{2} \times 139,35\right) \\
& T I C=\operatorname{Rp} 11.899 .992,00+17.790 .497,47 \\
& \text { TIC }=\operatorname{Rp~29.690.489,47} \\
& \text { TIC Plasticizer } 1=\left(\frac{D}{Q} S\right)+\left(\frac{Q}{2} H\right) \\
& T I C=\left(\frac{1.637 .219,00}{136.434,91} \times 891.666\right)+\left(\frac{136.434,91}{2} \times 260,80\right) \\
& T I C=\operatorname{Rp} 10.699 .992,52+\operatorname{Rp} 17.791 .112,26 \\
& T I C=\operatorname{Rp~28.491.104,78~}
\end{aligned}
$$

\section{B. Perhitungan Metode Economic Order Quantity (EOQ)}

Berdasarkan data yang diperoleh penelitian di PT. Sinarmonas Industries maka dapat diuraikan langkah-langkah dalam pembelian bahan baku yang ekonomis sebagai berikut:

1. Pembelian Polyvinyl Chloride

Biaya simpan Polyvinyl Chloride per tahun $(H)$ $139,35 / \mathrm{Kg}$

Kebutuhan Polyvinyl Chloride (D) 3.064.025,40 Kg/tahun

Biaya tiap kali pesan Polyvinyl Chloride(S) 991.666/pemesanan

Maka dapat diperhitungkan dengan metode Economic Order Quantity (EOQ) sebagai berikut:

$$
\begin{aligned}
& Q *=\sqrt{\frac{2 D S}{H}} \\
& Q *=\sqrt{\frac{2(3.064 .025,40)(991.666)}{139,35}} \\
& Q *=\sqrt{\frac{6.076 .979 .624 .632,80}{139,35}} \\
& Q *=\sqrt{43.609 .469 .857,42} \\
& Q *=208.828,80 \mathrm{Kg}
\end{aligned}
$$

\section{Pembelian Plasticizer 1}

Biaya simpan Plasticizer 1 per tahun $(\mathrm{H})$ $260,80 / \mathrm{Kg}$
Total Kebutuhan Plasticizer 1(D) 1.637.219,00 $\mathrm{Kg} /$ tahun

Biaya tiap kali pesan Plasticizer 1 (S) 891.666/pemesanan

Maka dapat diperhitungkan dengan metode Economic Order Quantity (EOQ) sebagai berikut:

$$
\begin{aligned}
& Q *=\sqrt{\frac{2 D S}{H}} \\
& Q *=\sqrt{\frac{2(1.637 .219,00)(891.666)}{260,80}} \\
& Q *=\sqrt{11.195 .188 .012,68} \\
& Q *=105.807,31 \mathrm{Kg}
\end{aligned}
$$

3. Frekuensi Pemesanan Bahan Baku

Frekuensi Pembelian Polyvinyl Chloride

$$
\begin{aligned}
F & =\frac{D}{Q *} \\
F & =\frac{3.064 .025,40 \mathrm{Kg}}{208.828,80 \mathrm{Kg}} \\
F & =14,67 \mathrm{Kali}(\text { Dibulatkan }=15 \mathrm{kali})
\end{aligned}
$$

Frekuensi Pembelian Plasticizer 1

$$
\begin{aligned}
F & =\frac{D}{Q *} \\
F & =\frac{1.637 .219,00 \mathrm{Kg}}{105.807,31 \mathrm{Kg}} \\
F & =15,47 \mathrm{Kali}(\text { Dibulatkan }=16 \mathrm{kali})
\end{aligned}
$$

4. Total Biaya Persediaan Total Inventory Cost (TIC) Berdasarkan Economic Order Quantity (EOQ)

TIC Polyvinyl Chloride

$$
\begin{aligned}
\text { TIC } & =\left(\frac{D}{Q *} S\right)+\left(\frac{Q *}{2} H\right) \\
\text { TIC } & =\left(\frac{3.064 .025,40}{208.828,80} \times 991.666\right)+\left(\frac{208.828 .80}{2} \times 139,35\right) \\
& =14.550 .147,35+14.550 .146,64 \\
& =R p 29.100 .293,99
\end{aligned}
$$

TIC Plasticizer 1

TIC $=\left(\frac{D}{Q *} S\right)+\left(\frac{Q *}{2} H\right)$

$T I C=\left(\frac{1.637 .219,00}{105.807,31} \times 891.666\right)+\left(\frac{105.807,31}{2} \times 260,80\right)$ 
$=13.797 .274,65+13.797 .273,22$

$=R p 27.594 .547,87$

5. Menentukan Persediaan Pengaman Safety Stock (SS)

Safety Stock Polyvinyl Chloride $=S D X Z$

$$
\begin{aligned}
& =68.452,56 \times 1,65 \\
& =112.946,73 \mathrm{Kg}
\end{aligned}
$$

Safety Stock Plasticizer $1=S D X Z$

$$
\begin{aligned}
& =33.672,57 \times 1,65 \\
= & 55.559,75 \mathrm{Kg}
\end{aligned}
$$

6. Menentukan Pemesanan kemabali Re Order Point (ROP)

Polyvinil Chloride $=(U x L)+S S($ Safety Stock $)$

$$
\begin{array}{r}
=(8.511,18 \times 3)+112.946,73 \\
=25.533,54+112.946,73 \\
=138.480,27 \mathrm{Kg}
\end{array}
$$

ROP Plasticizer $1=(U x L)+S S($ Safety Stock $)$

$$
\begin{aligned}
& =(4.547,83 \times 3) \\
& +33.67 \\
= & 13.643,49+33.672,57 \\
= & 47.316,06 \mathrm{Kg}
\end{aligned}
$$

\section{Perhitungan Metode Periode Order} Quantity (POQ)

1. POQ Polyvinil Chloride

$$
\begin{aligned}
P O Q & =\sqrt{\frac{2 \cdot P \cdot \bar{D}}{S}} \\
& =\sqrt{\frac{2(991.666 \times 255.335,45)}{139,35}} \\
& =\sqrt{3.634 .122 .488,11} \\
& =60.283,68 \mathrm{Kg}
\end{aligned}
$$

Frekuensi pemesanan:

$$
\begin{aligned}
f & =\frac{D}{Q} \\
& =\frac{255.335,45}{60.283,68}=4.23 \rightarrow 5 \text { kali }
\end{aligned}
$$

2. POQ Plasticizer 1

$$
\begin{aligned}
P O Q & =\sqrt{\frac{2 \cdot P \cdot \bar{D}}{S}} \\
& =\sqrt{\frac{2(891.666 \times 136.434,91}{260,80}} \\
& =\sqrt{932.932,288.80} \\
& =30.543,94 \mathrm{Kg}
\end{aligned}
$$

$$
\begin{aligned}
& \text { Frekuensi pemesanan: } \\
& \begin{aligned}
f & =\frac{D}{Q} \\
& =\frac{136.434,91}{30.543,94}=4,46 \rightarrow 5 \text { kali }
\end{aligned}
\end{aligned}
$$

3. Total Biaya Persediaan Total Inventory Cost (TIC) Berdasarkan Period Order Quantity (POQ)

Total biaya persediaan Polyvinyl Chloride $T I C=($ Frekuensi pesan X Biaya pesan $)$

TIC $=(5 \times 991.666,00)$

$$
\begin{aligned}
& +\left(\sum \frac{Q}{2}\right. \\
& + \text { Safety Stock }) X \text { Biaya simpan }
\end{aligned}
$$

$$
\begin{aligned}
& +\left(\frac{60.283,68}{2}\right. \\
& +112.946,73) \times 139,35
\end{aligned}
$$

$T I C=4.958 .330,00+19.939 .392,22$

$T I C=24.897 .722,22$

Total biaya persediaan Plasticizer 1

$$
T I C=(\text { Frekuensi pesan } X \text { Biaya pesan })
$$

$T I C=(5 \times 891.666)$

$$
\begin{aligned}
& +\left(\sum \frac{Q}{2}\right. \\
& + \text { Safety Stock }) \text { X Biaya simpan }
\end{aligned}
$$

$$
\begin{aligned}
& +\left(\frac{30.543,94}{2}\right. \\
& +33.672,57) \times 260,80
\end{aligned}
$$

$T I C=4.458 .330,00+12.764 .736,03$

$T I C=17.223 .066,03$

4. Menentukan Persediaan Pengaman Safety Stock (SS)

SS Polyvinyl Chloride $=S D X Z$

$$
\begin{aligned}
& =2.301,50 \times 1,65 \\
& =3.797 .47 \mathrm{Kg}
\end{aligned}
$$

SS Plasticizer $1=S D X Z$

$$
\begin{aligned}
& =1.095,40 \times 1,65 \\
& =1.807,41 \mathrm{Kg}
\end{aligned}
$$

5. Menentukan Pemesanan kemabali Re Order Point (ROP)

Polyvinil Chloride

$$
\begin{aligned}
\mathrm{ROP}=(U x L)+ & \text { SS }(\text { Safety Stock }) \\
& =(279,52 \times 3) \\
& +3.797,47 \\
& =838,56+3.797,47
\end{aligned}
$$




$$
=4.636,03 \mathrm{Kg}
$$

Plasticizer 1

$$
\begin{aligned}
\mathrm{ROP}=(U x L) & +S S(\text { Safety Stock }) \\
= & (149,52 \times 3) \\
& +1.807,41 \\
& =448.56+1.807,41 \\
& =2.255,97 \mathrm{Kg}
\end{aligned}
$$

\section{Perbandingan Persediaan Bahan Baku Antara Kebijakan Perusahaan Dengan Metode EOQ dan POQ}

Tabel 4.16 Perbandingan total biaya persediaan Polyvinyl Chloride kebijakan perusahaan dengan Metode EOQ dan POQ

\begin{tabular}{|c|c|c|c|c|}
\hline No & Keterangan & $\begin{array}{c}\text { Kebijakan } \\
\text { Perusahaan }\end{array}$ & Metod(EOQ) & Metod(POQ) \\
\hline 1 & $\begin{array}{c}\text { Pembeliaan } \\
\text { Rata-rata }\end{array}$ & $\begin{array}{c}255.335,45 \\
\text { Kg }\end{array}$ & $\begin{array}{c}208.828,80 \\
\text { Kg }\end{array}$ & $60.283,68 \mathrm{Kg}$ \\
\hline 2 & $\begin{array}{c}\text { Frekuensi } \\
\text { Pembelian }\end{array}$ & $12 \mathrm{Kali}$ & $15 \mathrm{Kali}$ & $5 \mathrm{Kali}$ \\
\hline 3 & $\begin{array}{c}\text { Total Biaya } \\
\text { Persediaan }\end{array}$ & $\begin{array}{c}\mathrm{Rp} \\
29.690 .489,47 \\
/ \text { tahun }\end{array}$ & $\begin{array}{c}29.100 .293,99 \\
/ \text { tahun }\end{array}$ & $\begin{array}{c}\text { Rp } \\
24.897 .722,22 \\
/ \text { tahun }\end{array}$ \\
\hline 4 & Safety Stock & - & $112.946,73 \mathrm{~kg}$ & $3.797,47 \mathrm{Kg}$ \\
\hline 5 & $\begin{array}{c}\text { Re Order } \\
\text { Point (ROP) }\end{array}$ & - & $138.480,27 \mathrm{~kg}$ & $4.636,03 \mathrm{Kg}$ \\
\hline
\end{tabular}

(Sumber: Pengolahan Data Sendiri di PT. Sinarmonas Industries)

Tabel 4.17 Perbandingan total biaya persediaan Plasticizer 1 kebijakan perusahaan dengan Metode EOQ dan POQ

\begin{tabular}{|c|c|c|c|c|}
\hline No & Keterangan & $\begin{array}{c}\text { Kebijakan } \\
\text { Perusahaan }\end{array}$ & Metod(EOQ) & Metod(POQ) \\
\hline 1 & $\begin{array}{c}\text { Pembeliaan } \\
\text { Rata-rata }\end{array}$ & $\begin{array}{c}136.434,91 \\
\mathrm{Kg}\end{array}$ & $\begin{array}{c}105.807,31 \\
\mathrm{Kg}\end{array}$ & $30.543,94 \mathrm{Kg}$ \\
\hline 2 & $\begin{array}{c}\text { Frekuensi } \\
\text { Pembelian }\end{array}$ & $12 \mathrm{Kali}$ & $16 \mathrm{Kali}$ & $5 \mathrm{Kali}$ \\
\hline 3 & $\begin{array}{c}\text { Total Biaya } \\
\text { Persediaan }\end{array}$ & $\begin{array}{c}\mathrm{Rp} \\
28.491 .104,78 \\
\text { /tahun }\end{array}$ & $\begin{array}{c}\mathrm{Rp} \\
27.594 .547,87 \\
\text { /tahun }\end{array}$ & $\begin{array}{c}\mathrm{Rp} \\
17.223 .066,03 \\
\text { /tahun }\end{array}$ \\
\hline 4 & Safety Stock & - & $55.559,75 \mathrm{Kg}$ & $1.807,41 \mathrm{Kg}$ \\
\hline 5 & $\begin{array}{c}\text { Re Order } \\
\text { Point (ROP) }\end{array}$ & - & $47.316,06 \mathrm{Kg}$ & $2.255,97 \mathrm{Kg}$ \\
\hline
\end{tabular}

(Sumber: Hasil pengolahan data di PT. Sinarmonas Industries)

\section{KESIMPULAN}

Berdasarkan hasil penelitian yang dilakukan penulis di PT. XYZ maka dapat ditarik kesimpulan yang dapat dijadikan pertimbangan dan bermanfaat bagi perusahaan. Adapun kesimpunnya sebagai berikut:
1. Untuk pemesanan Optimum dengan metode EOQ Polyvinyl Chloride sebesar 208.828,80 Kg dan Plasticizer 1 $105.807,31 \mathrm{Kg}$ sedangkan menggunakan POQ Polyvinyl Chloride sebesar 60.283,68 $\mathrm{Kg}$ dan Plasticizer $130.543,94 \mathrm{Kg}$.

2. Titik pemesanan kembali Re Order Point (ROP) dengan menggunakan metode metode EOQ yaitu bahan baku Polyvinyl Chloride sebesar $138.480,27 \mathrm{~kg}$ dan Plasticizer 1 47.316,06 Kg Sedangkan Menggunakan Metode POQ Bahan baku Polyvinyl Chloride sebesar $4.636,03 \mathrm{Kg}$ dan Plasticizer $12.255,97 \mathrm{~kg}$.

3. Total biaya persediaan dengan menggunakan metode EOQ bahan baku Polyvinyl Chloride sebesar Rp 29.100.293,99/ tahun dan Plasticizer $1 \mathrm{Rp}$ 27.594.547,87/tahun dan POQ bahan baku Polyvinyl Chloride sebesar Rp 24.897.722,22 / tahun dan Plasticizer 1 Rp 17.223.066,03/tahun.

\section{DAFTAR PUSTAKA}

Agus, R. (2009). Manajemen persediaan. Yogyakarta: Graha Ilmu.

Alfatiyah, R. (2017). Perencanaan Produksi Minyak Telon Ukuran 100 Ml Dengan Metode Time Series Di PT. MERPATI MAHARDIKA. Teknik Industri, $9(25)$.

Assauri, S. (2008). Manajemen Produksi dan Operasi edisi revisi. Jakarta: Lembaga Penerbit Fakultas Ekonomi Universitas Indonesia.

Bastuti, S., Alfatiyah, R., Shobur, M., \& Candra, A. (2019). Manajemen Logistik.

Bastuti, S., \& Teddy, T. (2017, December). Analisis Persediaan Barang Dengan Metode Time Series Dan Sistem Distribution Requirement Planning Untuk Mengoptimalkan Permintaan Barang Di Pt. Asri Mandiri Gemilang. In Proceedings (Vol. 2, No. 1). 
Indriyo, G. (2012). Manajemen Pemasaran. edisi kedua, cetakan kedua. Penerbit: BPFE-Yogyakarta.

Kurnia, D., Bastuti, S., \& Istiqomah, B. N. (2018). Analisis Pengendalian Bahan Baku Pada Produk Tas Dengan Menggunakan Metode Material Requirements Planning (Mrp) Untuk Meminimalkan Biaya Penyimpanan Di Home Industry Amel Collection. Jitmi (Jurnal Ilmiah Teknik Dan Manajemen Industri), 1(1), 22-28.

Murty, D. H., \& Jazuli, T. T. Optimasi Pengendalian Persediaan Bahan Baku Di Pt. Bromindo Mekar Mitra.

M. Trihudiyatmanto, 2016. Persediaan bahan baku dengan menggunakan metode Economic Order Quantity (EOQ), Fakultas Ekonomi Sains Al Qur'an Program Study Manajemen, Studi Kasus CV. Jaya Gemilang Wonosobo.

Putri, N. N., Sudono, A., \& Riyadi, D. (2016). Aplikasi Metode Economic Order Quantity (Eoq) Terhadap Total Biaya Persediaan Bahan Baku Makanan Groceries \& Dairy Product Di Banana Inn Hotel Kota Bandung. Gastronomy Tourism Journal, 3(1), 265-273.

Sari, S. P. (2010). Pengoptimalan persediaan bahan baku kacang tanah menggunakan metode EOQ (Economic Order Quantity) di PT. Dua Kelinci Pati.

Santria, F. E. (2010). Analisis pengendalian persediaan bahan baku dengan metode eoq pada perusahaan handuk Lumintu di Klaten.

Sigit, A. (2016). Studi Komparasi Metode Eoq Dan Poq Dalam Efisiensi Biaya Persediaan Material Paving Block. Jurnal Teknisia, 21(1), 209-217. 